\title{
The distribution of blood eosinophil levels in a Japanese COPD clinical trial database and in the rest of the world
}

This article was published in the following Dove Press journal: International Journal of COPD

\author{
Neil Barnes ${ }^{1,2}$ \\ Takeo Ishii ${ }^{3,4}$ \\ Nobuyuki Hizawa ${ }^{5}$ \\ Dawn Midwinter 6 \\ Mark James ${ }^{3}$ \\ Emma Hilton \\ Paul W Jones ${ }^{1,7}$
}

'Respiratory Medicine Franchise, GlaxoSmithKline, Brentford, UK; ${ }^{2}$ William Harvey Research Institute, Barts and The London School of Medicine and Dentistry, London, UK; ${ }^{3}$ Medical Affairs, GlaxoSmithKline K.K., Tokyo, Japan; ${ }^{4}$ Graduate School of Medicine, Nippon Medical School, Tokyo, Japan; ${ }^{5}$ Department of Pulmonary Medicine, Faculty of Medicine, University of Tsukuba, Tsukuba, Japan; ${ }^{6}$ Global Respiratory Department, GlaxoSmithKline, Stockley Park, UK; ${ }^{7}$ Institute of Infection and Immunity, St George's University of London, London, UK
Correspondence: Neil Barnes Respiratory Medicine Franchise, GlaxoSmithKline, 980 Great West Road, Brentford, TW8 9GS, UK

Tel +447552 283420

Email neil.c.barnes@gsk.com
Background: Blood eosinophil measurements may help to guide physicians on the use of inhaled corticosteroids (ICS) for patients with chronic obstructive pulmonary disease (COPD). Emerging data suggest that COPD patients with higher blood eosinophil counts may be at higher risk of exacerbations and more likely to benefit from combined ICS/long-acting beta 2 -agonist (LABA) treatment than therapy with a LABA alone. This analysis describes the distribution of blood eosinophil count at baseline in Japanese COPD patients in comparison with non-Japanese COPD patients.

Methods: A post hoc analysis of eosinophil distribution by percentage and absolute cell count was performed across 12 Phase II-IV COPD clinical studies (seven Japanese studies [N=848 available absolute eosinophil counts] and five global studies [N=5,397 available eosinophil counts] that included 246 Japanese patients resident in Japan with available counts). Blood eosinophil distributions were assessed at baseline, before blinded treatment assignment.

Findings: Among Japanese patients, the median (interquartile range) absolute eosinophil count was 170 cells $/ \mathrm{mm}^{3}\left(100-280\right.$ cells $\left./ \mathrm{mm}^{3}\right)$. Overall, 612/1,094 Japanese patients (56\%) had an absolute eosinophil count $\geq 150$ cells $/ \mathrm{mm}^{3}$ and $902 / 1,304$ Japanese patients $(69 \%)$ had a percentage eosinophil $\geq 2 \%$. Among non-Japanese patients, these values were $160(100-250)$ cells $/ \mathrm{mm}^{3}$, $2,842 / 5,151$ patients $(55 \%)$, and $2,937 / 5,155$ patients $(57 \%)$, respectively. The eosinophil distribution among Japanese patients was similar to that among non-Japanese patients. Within multi-country studies with similar inclusion criteria, the eosinophil count was numerically lower in Japanese compared with non-Japanese patients (median 120 vs 160 cells $/ \mathrm{mm}^{3}$ ).

Interpretation: The eosinophil distribution in Japanese patients seems comparable to that of non-Japanese patients; although within multi-country studies, there was a slightly lower median eosinophil count for Japanese patients compared with non-Japanese patients. These findings suggest that blood eosinophil data from global studies are of relevance in Japan.

Keywords: COPD, blood eosinophil count, percentage blood eosinophil, Japan

\section{Introduction}

Post hoc analyses of two clinical trials showed that there is evidence that a higher blood eosinophil count may be predictive of a higher risk of exacerbations for chronic obstructive pulmonary disease (COPD) patients with an exacerbation history who were treated with long-acting beta ${ }_{2}$-agonists (LABA), without inhaled corticosteroids (ICS). ${ }^{1,2}$ Recent data suggest that patients with higher blood eosinophil levels may be more likely to benefit from combined ICS/LABA treatment than therapy with a LABA alone. ${ }^{1,3-7}$ Moreover, the use of eosinophils as a potential biomarker to identify specific disease subtypes - or endotypes - for which treatment can be tailored to individual patients 
has recently been discussed for COPD and other chronic lung conditions. ${ }^{8}$ For these reasons, blood eosinophil measurements have the potential to help guide physicians on the use of ICS with regard to exacerbation prevention, but, as pointed out in the recent Global Initiative for Chronic Obstructive Lung Disease (GOLD) guidelines, the data are not conclusive, and prospective clinical trials are needed before this can be recommended for daily clinical practice. ${ }^{9}$

Ethnicity has been reported to have little impact on eosinophil levels, ${ }^{10}$ but blood eosinophil levels can be elevated within and above the normal range in a number of conditions, including allergies and parasitic/fungal infections, ${ }^{11,12}$ and by external stimuli, such as smoking and exercise. ${ }^{13,14}$ However, blood eosinophil levels do not seem to be influenced by the use of ICS. ${ }^{15,16}$ As these external factors can vary between countries, it is possible that there may be differences in the distribution of eosinophil levels in patients with COPD between countries, although, in a post hoc analysis, the distribution of blood eosinophil counts in COPD patients in UK trials was similar to the distribution in patients from the rest of the world. ${ }^{17}$

As current evidence supports eosinophils as a potential biomarker, the primary objective of this analysis was to investigate the distribution of blood eosinophil counts at baseline in randomized, controlled trials recruiting Japanese patients with COPD and compare the eosinophil distribution at baseline in Japanese versus non-Japanese patients.

\section{Methods}

\section{Study design}

A post hoc analysis of blood eosinophil distribution at baseline was performed using data from the GlaxoSmithKline COPD clinical trial database. All individual trials examined in this post hoc analysis were approved by the appropriate regulatory organizations.

The inclusion criteria used to select studies for this analysis were any GlaxoSmithKline Research and Development or local GlaxoSmithKline-sponsored Phase II-IV randomized clinical trials conducted from 1999 to 2016 that recruited Japanese patients and included any of GSK961081, fluticasone furoate, fluticasone propionate, salmeterol, umeclidinium, vilanterol, alone, or as a dual combination as a randomized study drug for COPD, and for which individual patient baseline or screening blood eosinophil counts were available. As individual patient data were not available in the published papers, non-GlaxoSmithKline and investigator-sponsored studies were not included. We also excluded studies reporting data from a single country only (outside Japan).
Across the individual studies included in this analysis, patient inclusion/exclusion criteria were mainly based on COPD diagnosis, forced expiratory volume in 1 second $\left(\mathrm{FEV}_{1}\right)$ at entry, prior exacerbation history, previous/current diagnosis of asthma, smoking history, and reversible airflow limitation. None of the included studies used blood eosinophil count as an inclusion or exclusion criterion. A summary of the criteria for each trial is provided in Table S1 and further information on the designs of the trials is available on ClinicalTrials.gov.

The included studies were categorized into Japan-only studies and multi-country studies that recruited Japanese patients living in Japan. This is a post hoc analysis of study data, and, although the studies themselves all received ethical approval, the current analysis did not require additional ethical approval.

\section{Assessments}

Blood samples for eosinophil assessments were taken according to routine laboratory screening as described in each individual study protocol. The earliest individual patient pre-randomization eosinophil values, prior to any ICS or oral corticosteroid run-in, were selected for use in the analysis, although not all patients were ICS naïve at the time of recruitment. Data on the number of patients who were not ICS naïve at the time of recruitment in each study or in each group were not available for inclusion in these analyses. Values were presented as absolute blood eosinophil counts and percentage blood eosinophils.

\section{Statistical analyses and data presentation}

No formal statistical testing was performed. Japanese patient data from all of the studies were the primary focus of the analysis. Histograms of baseline eosinophil counts were produced. Summary tables of the proportion of patients by baseline absolute eosinophil subgroups $\left(<100, \geq 100 ;<150, \geq 150 ;<300, \geq 300\right.$ cells $\left./ \mathrm{mm}^{3}\right)$ and percentage eosinophil subgroups $(<2 \%, \geq 2 \%)$ were produced for Japanese patients only, both overall (Group 1: Japan-only studies combined with Japanese data from multicountry studies) and by study.

A cumulative density function was produced to enable a visual comparison of the distribution of absolute eosinophils. A line for Group 1 and each of the four following groups was overlaid into a single plot; Group 2 - all patient data from Japan-only studies; Group 3 - all patient data from multi-country studies; Group 4 - Japanese patient data from multi-country studies; Group 5 - non-Japanese patient data from multi-country studies. 
Summary tables for Groups 1-5, based on absolute eosinophil count $\left(<150, \geq 150\right.$ cells $\left./ \mathrm{mm}^{3}\right)$ and percentage eosinophils ( $<2 \%, \geq 2 \%$ ), were also produced to compare baseline demographics and COPD disease characteristics (GOLD 2006 distribution [I-IV], St George's Respiratory Questionnaire [SGRQ] score, and history of exacerbation). Data are presented from all Japanese patients (Group 1) alongside data from non-Japanese patients recruited to multicountry studies (Group 5).

\section{Results \\ Included studies}

In total, 12 studies (seven Japan-only; five multi-country) met the inclusion criteria and were included in this analysis (Table S1). The seven Japan-only studies were: SCO100646 (NCT00269126), SCO100648 (NCT00269087), HZC114156 (NCT01192191), DB2115362 (NCT01376388), AC4115361 (NCT01702363), SCO116571 (NCT01607398), ${ }^{18}$ and SCO116717 (COSMOS-J; NCT01762800). ${ }^{19}$ Study SCO116717 did not include data for absolute eosinophil count. The five multi-country studies included were: HZC112206 (NCT01053988), ${ }^{20}$ HZC1 12207 (NCT01054885), ${ }^{19}$ DB2 113361 (NCT01313637), ${ }^{21}$ DB2 113373 (NCT01313650), ${ }^{22}$ and AC4115408 (NCT01387230). ${ }^{23}$

\section{Trial participants}

Absolute blood eosinophil count data were available from 6,245 trial participants, comprising 1,094 Japanese patients (848 from Japan-only studies; 246 from multi-country studies) and 5,151 non-Japanese patients from multi-country studies. Percentage blood eosinophil data were available from 6,459 patients, comprising 1,304 Japanese patients (1,058 from Japan-only studies; 246 from multi-country studies) and 5,155 non-Japanese patients.

Baseline demographics and disease characteristics of all Japanese patients and non-Japanese patients from multicountry studies are shown in patients with available absolute blood eosinophil count in Table 1 and by percentage blood eosinophils and absolute eosinophils in Table S2. Baseline demographics and disease characteristics of patients in Japanonly studies according to absolute eosinophils are shown in Table S3. Baseline characteristics were broadly comparable among Japanese and non-Japanese patients for most categories (Table 1), as well as comparable across percentage eosinophil subgroups $(<2 \%, \geq 2 \%)$ within each of these two patient groups (Table S2). However, a higher proportion of Japanese patients were male, $\geq 65$ years of age, or were exacerbation-free in the 12 months prior to the study, compared with non-Japanese patients, and slightly more non-Japanese patients had GOLD stage III disease than Japanese patients (Tables 1 and $\mathrm{S} 2$ ). In addition, the SGRQ total score seemed lower in Japanese than in non-Japanese patients, although it should be noted that SGRQ data were only available for three of the multi-country studies, and patient numbers were low.

There was no apparent relationship between baseline eosinophil levels and exacerbation burden (Table S2), but no formal correlation analysis was performed.

\section{Blood eosinophil distribution}

A summary of absolute and percentage blood eosinophil counts in all five patient groups is shown in Table 2. Among Japanese patients, the median absolute blood eosinophil count was 170 cells $/ \mathrm{mm}^{3}$, and $56 \%$ had an absolute blood eosinophil count $\geq 150$ cells $/ \mathrm{mm}^{3}$, with $69 \%$ having a percentage blood eosinophil $\geq 2 \%$; among non-Japanese patients, these values were 160 cells $/ \mathrm{mm}^{3}, 55 \%$, and $57 \%$, respectively (Table 2).

The distribution of absolute blood eosinophil count among Japanese patients was comparable to the distribution among non-Japanese patients (Figure 1). However, the absolute blood eosinophil count was numerically lower in Japanese patients than in non-Japanese patients in the multicountry studies (median $120 \mathrm{cells} / \mathrm{mm}^{3}$ vs 160 cells $/ \mathrm{mm}^{3}$, respectively) (Table 2). The distributions of absolute blood eosinophil count and percentage blood eosinophils among all Japanese patients are shown in Figure 2A and B.

\section{Discussion}

The primary objective of the current analysis was to investigate the distribution of baseline blood eosinophil counts in Japanese COPD patients across GlaxoSmithKlineResearch and Development or local GlaxoSmithKline sponsored Phase II-IV randomized clinical trials of COPD therapies conducted from 1999 to 2016 that recruited Japanese patients and had available individual patient baseline/screening blood eosinophil counts. We also evaluated blood eosinophil distribution in non-Japanese COPD patients in multi-country studies. While no formal statistical testing was performed, we found that the distribution of absolute blood eosinophil counts in Japanese COPD patients across all studies was similar to the distribution in non-Japanese patients. However, when considering the multi-country studies only, the median blood eosinophil count was numerically lower in Japanese than in non-Japanese COPD patients. This difference may represent a more reliable reflection of the differences between 
Table I Patient demographics

\begin{tabular}{|c|c|c|c|}
\hline Characteristics & $\begin{array}{l}\text { All studies, } \\
\text { Japanese patients } \\
(\mathbf{N}=I, 094)\end{array}$ & $\begin{array}{l}\text { Multi-country studies, } \\
\text { non-Japanese patients } \\
(\mathrm{N}=5,15 \mathrm{I})\end{array}$ & $\begin{array}{l}\text { Multi-country studies, } \\
\text { Japanese patients } \\
(\mathrm{N}=\mathbf{2 4 6})\end{array}$ \\
\hline Age (years), mean (SD) & $70(7.4)$ & $62(8.7)$ & $69(7.4)$ \\
\hline \multicolumn{4}{|l|}{ Age (years), n (\%) } \\
\hline$<65$ & $257(23)$ & 3,029 (59) & $68(28)$ \\
\hline$\geq 65$ & $837(77)$ & $2,122(4 I)$ & $178(72)$ \\
\hline Male, n (\%) & ।,037 (95) & $3,454(67)$ & $234(95)$ \\
\hline \multicolumn{4}{|l|}{ GOLD stage, n (\%) } \\
\hline $\mathrm{n}$ & $\mathrm{I}, 042$ & 5,128 & 245 \\
\hline I: $\quad F E V_{1} \geq 80 \%$ predicted & $\mathrm{I}(<\mathrm{I})$ & $2(<1)$ & 0 \\
\hline II: $50 \% \leq \mathrm{FEV}_{1}<80 \%$ predicted & $586(56)$ & $2,370(46)$ & $|4|(58)$ \\
\hline III: $30 \% \leq \mathrm{FEV}_{1}<50 \%$ predicted & 407 (39) & $2,263(44)$ & $83(34)$ \\
\hline IV: $\mathrm{FEV}_{1}<30 \%$ predicted & $48(5)$ & $493(10)$ & $21(9)$ \\
\hline \multicolumn{4}{|l|}{ SGRQ total score } \\
\hline $\mathrm{n}$ & $156^{\mathrm{a}}$ & $2,904^{a}$ & $156^{\mathrm{a}}$ \\
\hline Mean (SD) & $39.4(15.64)$ & $48.9(17.66)$ & $39.4(15.64)$ \\
\hline \\
\hline \multicolumn{4}{|c|}{ without oral/systemic corticosteroids and/or antibiotics } \\
\hline \multicolumn{4}{|c|}{ (not involving hospitalization) in the past 12 months, $\mathrm{n}(\%)$} \\
\hline $\mathrm{n}$ & $537^{b}$ & $2,140^{c}$ & $89^{d}$ \\
\hline 0 & $523(97)$ & I,900 (89) & $86(97)$ \\
\hline 1 & $14(3)$ & $209(10)$ & $3(3)$ \\
\hline 2 & 0 & $25(1)$ & 0 \\
\hline$>2$ & 0 & $6(<1)$ & 0 \\
\hline \\
\hline \multicolumn{4}{|c|}{ oral/systemic corticosteroids and/or antibiotics (not } \\
\hline \multicolumn{4}{|c|}{ involving hospitalization) in the past 12 months, $\mathrm{n}(\%)$} \\
\hline $\mathrm{n}$ & $694^{\mathrm{e}}$ & 5,151 & 246 \\
\hline 0 & $612(88)$ & $3,822(74)$ & $217(88)$ \\
\hline 1 & $59(9)$ & $\mathrm{I}, 034(20)$ & $20(8)$ \\
\hline 2 & $15(2)$ & $199(4)$ & $4(2)$ \\
\hline$>2$ & $8(1)$ & $96(2)$ & $5(2)$ \\
\hline \multicolumn{4}{|c|}{ Number of patients with COPD exacerbations requiring } \\
\hline \multicolumn{4}{|c|}{ hospitalization in the past 12 months, $\mathrm{n}(\%)$} \\
\hline $\mathrm{n}$ & $1,043^{f}$ & 5,151 & 246 \\
\hline 0 & $\mathrm{I}, 008(97)$ & $4,664(91)$ & $239(97)$ \\
\hline I & $33(3)$ & $437(8)$ & $7(3)$ \\
\hline 2 & $2(<1)$ & $43(<1)$ & 0 \\
\hline$>2$ & 0 & $7(<\mathrm{I})$ & 0 \\
\hline
\end{tabular}

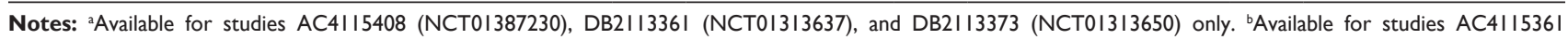
(NCTOI702363), DB2II5362 (NCT0I376388), HZCII2206 (NCTOI053988), HZCII2207 (NCTOI054885), and HZCII4I56 (NCTOII92I9I) only. 'Available for studies HZCII 2206 (NCTOI053988), and HZCII2207 (NCT0I054885) only. 'Not available for studies AC4II5408 (NCT0I387230), DB2II336I (NCT0I3I3637), and DB2II 3373 (NCTOI313650). eNot available for studies SCOI00646 (NCT00269126), SCOI00648 (NCT00269087), and SCOII657I (NCT0I607398). 'Not available for study SCOII657I (NCT01607398).

Abbreviations: SD, standard deviation; GOLD, Global Initiative for Chronic Obstructive Lung Disease; FEV , forced expiratory volume in I second; SGRQ, St George's Respiratory Questionnaire; COPD, chronic obstructive pulmonary disease.

Japanese patients resident in Japan and non-Japanese patients recruited elsewhere in the world, as the inclusion criteria for Japanese and non-Japanese patients were the same within each multi-country trial. However, it should be noted that the sample size for this analysis was small.

One reason for the observed small difference in eosinophil count between Japanese and non-Japanese patients may be the differences in the way COPD patients are diagnosed in Western countries and in Japan. In Japan, there is a tendency to exclude patients with any features suggestive of asthma from a COPD diagnosis, and there is a lower diagnosis rate for COPD, especially in younger patients, with milder disease. ${ }^{24-27}$ Consistent with this, our analysis found that, compared with non-Japanese patients, a numerically higher proportion of Japanese patients overall and those in Japanonly studies were older ( $\geq 65$ years), male, and with no recent history of exacerbations requiring corticosteroids and/ or antibiotics. The greater predominance of older Japanese male COPD patients is typical of other Japanese studies in clinical settings. ${ }^{26-28}$ However, the data from the Japanese 
Table 2 Summary of absolute and percentage blood eosinophil count across the five patient groups

\begin{tabular}{|c|c|c|c|c|c|}
\hline & $\begin{array}{l}\text { All studies, } \\
\text { Japanese patients } \\
(n=1,094)\end{array}$ & $\begin{array}{l}\text { Japan-only } \\
\text { studies } \\
(n=848)\end{array}$ & $\begin{array}{l}\text { Multi-country } \\
\text { studies } \\
(n=5,397)\end{array}$ & $\begin{array}{l}\text { Multi-country studies, } \\
\text { Japanese patients } \\
(\mathrm{n}=\mathbf{2 4 6})\end{array}$ & $\begin{array}{l}\text { Multi-country studies, } \\
\text { non-Japanese patients } \\
(n=5,151)\end{array}$ \\
\hline \multicolumn{6}{|c|}{ Absolute blood eosinophil count, cells $/ \mathrm{mm}^{3}$} \\
\hline Mean $(S D)^{\mathrm{a}}$ & $216.9(192.09)$ & $228.6(191.70)$ & $207.0(207.53)$ & I76.7 (I88.34) & $208.4(208.3 \mathrm{I})$ \\
\hline Median $(\mathrm{IQR})^{\mathrm{a}}$ & $170(100-280)$ & $180(|| 0-28 \mid)$ & $160(90-250)$ & $120(50-260)$ & $160(100-250)$ \\
\hline$<150$ cells $/ \mathrm{mm}^{3}(\mathrm{n}[\%])$ & $482(44 . I)^{b}$ & $343(40.4)^{c}$ & $2,448(45.4)^{d}$ & $139(56.5)^{d}$ & $2,309(44.8)^{\mathrm{d}}$ \\
\hline$\geq 150$ cells $/ \mathrm{mm}^{3}(\mathrm{n}[\%])$ & $612(55.9)^{\mathrm{b}}$ & $505(59.6)^{c}$ & $2,949(54.6)^{d}$ & $107(43.5)^{\mathrm{d}}$ & $2,842(55.2)^{d}$ \\
\hline \multicolumn{6}{|c|}{ Percentage blood eosinophil count } \\
\hline & $(n=1,304)$ & $(n=1,058)$ & $(n=5,40 I)$ & $(n=246)$ & $(n=5,155)$ \\
\hline$<2 \%$ eosinophils ( $\mathrm{n}[\%]$ ) & $402(30.8)^{b}$ & $274(25.9)^{c}$ & $2,346(43.4)^{d}$ & $128(52.0)^{\mathrm{d}}$ & $2,218(43.0)^{d}$ \\
\hline$\geq 2 \%$ eosinophils ( $\mathrm{n}[\%]$ ) & $902(69.2)^{b}$ & $784(74.1)^{c}$ & $3,055(56.6)^{d}$ & $118(48.0)^{d}$ & $2,937(57.0)^{d}$ \\
\hline
\end{tabular}

Notes: ajapan-only studies: AC4II536I (NCT0I702363), DB2II5362 (NCT01376388), HZCII4I56 (NCT0I192191), SCOI00646 (NCT00269I26), SCOI00648 (NCT00269087), and SCOII657I (NCT01607398). Study SCOII67I7 (NCT0I762800) is Japan-only but absolute eosinophil values are not available. Multi-country studies: AC4II5408 (NCTOI387230), DB2II336I (NCT0I3I3637,) DB2II3373 (NCTOI3I3650), HZCII2206 (NCT0I053988), and HZCII2207 (NCT0I054885). All studies: Japan-only studies and Multi-country studies combined. 'bStudies AC4II5408 (NCT0I387230), AC4II536I (NCT0I702363), DB2II336I (NCT0|3/3637), DB2II3373 (NCTOI3I3650), DB2II5362 (NCT0I376388), HZCII2206 (NCTOI053988), HZCII2207 (NCT0I054885), HZCII4I56 (NCT0II92I9I), SCOI00646 (NCT00269126), SCOI00648 (NCT00269087), and SCOII657I (NCTOI607398) are included. For studies SCOI00646 (NCT00269I26), SCOI00648 (NCT00269087), and SCOII657I (NCT01607398) subjects in FAS population are included. For percentage eosinophils, study SCOII67I7 (NCT0I762800) was also included. 'Studies AC4II536I (NCTOI702363), DB2II5362 (NCTOI376388), HZCII4I56 (NCTOII92I9I), SCOI00646 (NCT00269I26), SCOI00648 (NCT00269087), and SCOII657I (NCT0I607398) are included. For studies SCOI00646 (NCT00269126), SCOI00648 (NCT00269087), and SCOII657I (NCT01607398) subjects in the full analysis

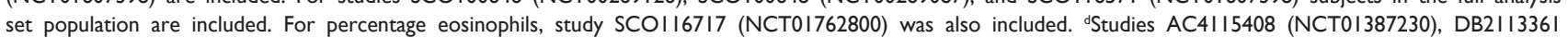
(NCT0 I I 3637), DB2I I 3373 (NCTOI 3 3650), HZCI 2206 (NCT0I 053988), and HZCI I 2207 (NCT0 I054885). are included.

Abbreviations: IQR, interquartile range; FAS, full analysis set; SD, standard deviation.

population in the current study show that, despite the exclusion of patients with asthma, a proportion of patients have high eosinophil counts. Of note, one included study (the Japanese COSMOS-J trial; Table S1 $),{ }^{18}$ of 400 patients with COPD, did not exclude patients with asthma.

Another possible reason for differences in eosinophil count between Japanese and non-Japanese patients may be due to local differences in the use of macrolides. Long-term prophylactic use of macrolides has been reported to reduce the frequency of exacerbations in patients with $\mathrm{COPD},{ }^{29}$ and macrolides can reduce eosinophil count. ${ }^{30}$ Unfortunately no data on the use of macrolides were available for patients in the included studies.

Data from two previous randomized, controlled trials indicate that patients with a blood eosinophil count $\geq 2 \%$ have a higher risk of exacerbation than patients with lower eosinophil levels. ${ }^{1,31}$ In the current analysis, there was no difference in the proportions of Japanese or non-Japanese patients with a prior history of COPD exacerbations between the $<2 \%$ and $\geq 2 \%$ eosinophil count subgroups. Blood eosinophil levels

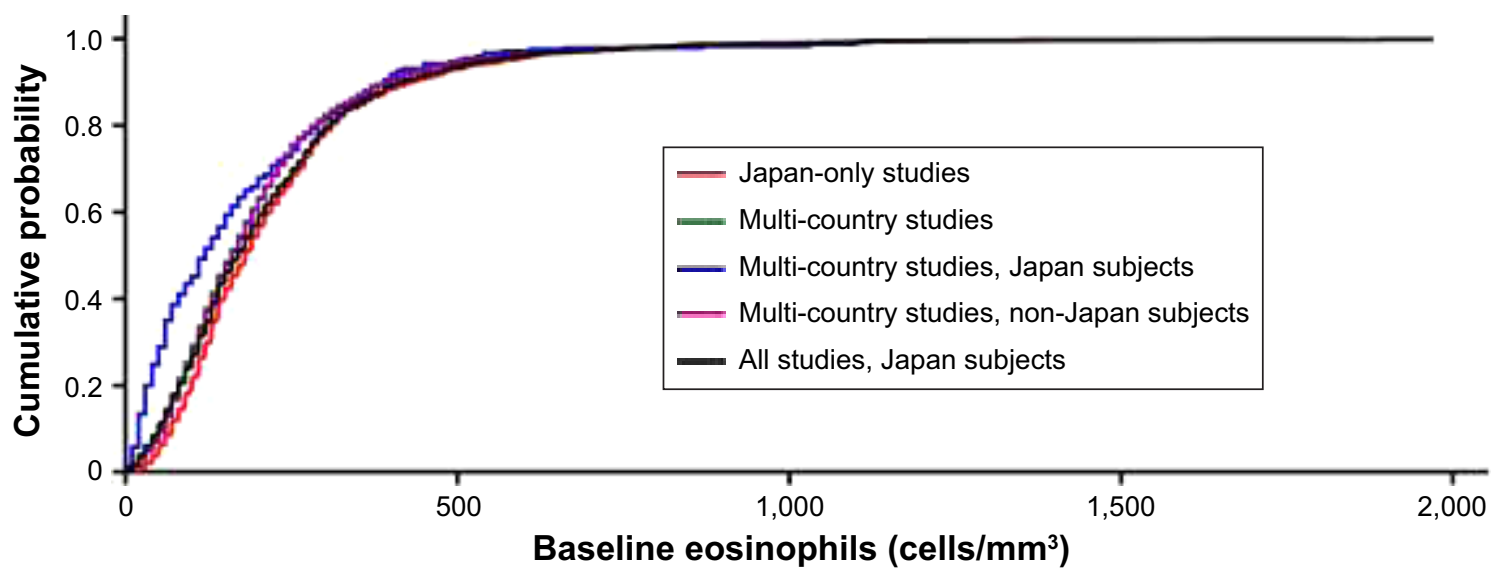

Figure I Japan-specific data distribution for absolute blood eosinophil count compared with other groups.

Notes: An empirical cumulative distribution function plot was produced to evaluate the distribution of absolute blood eosinophil count data, with a line for each of the five patient groups overlaid into a single plot. The lines show the cumulative probability for subjects in the specified group. Japan only studies: AC4I I536I (NCT0I702363), DB2II5362 (NCT0I376388), HZCII4I56 (NCT0II92I9I), SCOI00646 (NCT00269I26), SCOI00648 (NCT00269087), and SCOII657I (NCT0I607398). The absolute eosinophil values were not available for the Japan-only study, SCOI I67I 7 (NCT0 I 762800). Multi-country studies: AC4 I I 5408 (NCT0 I 387230), DB2 I I336 I (NCT0 I 3 I 3637), DB2II 3373 (NCTOI3I3650), HZCII 2206 (NCT0I053988), and HZCII 2207 (NCT0I054885). 

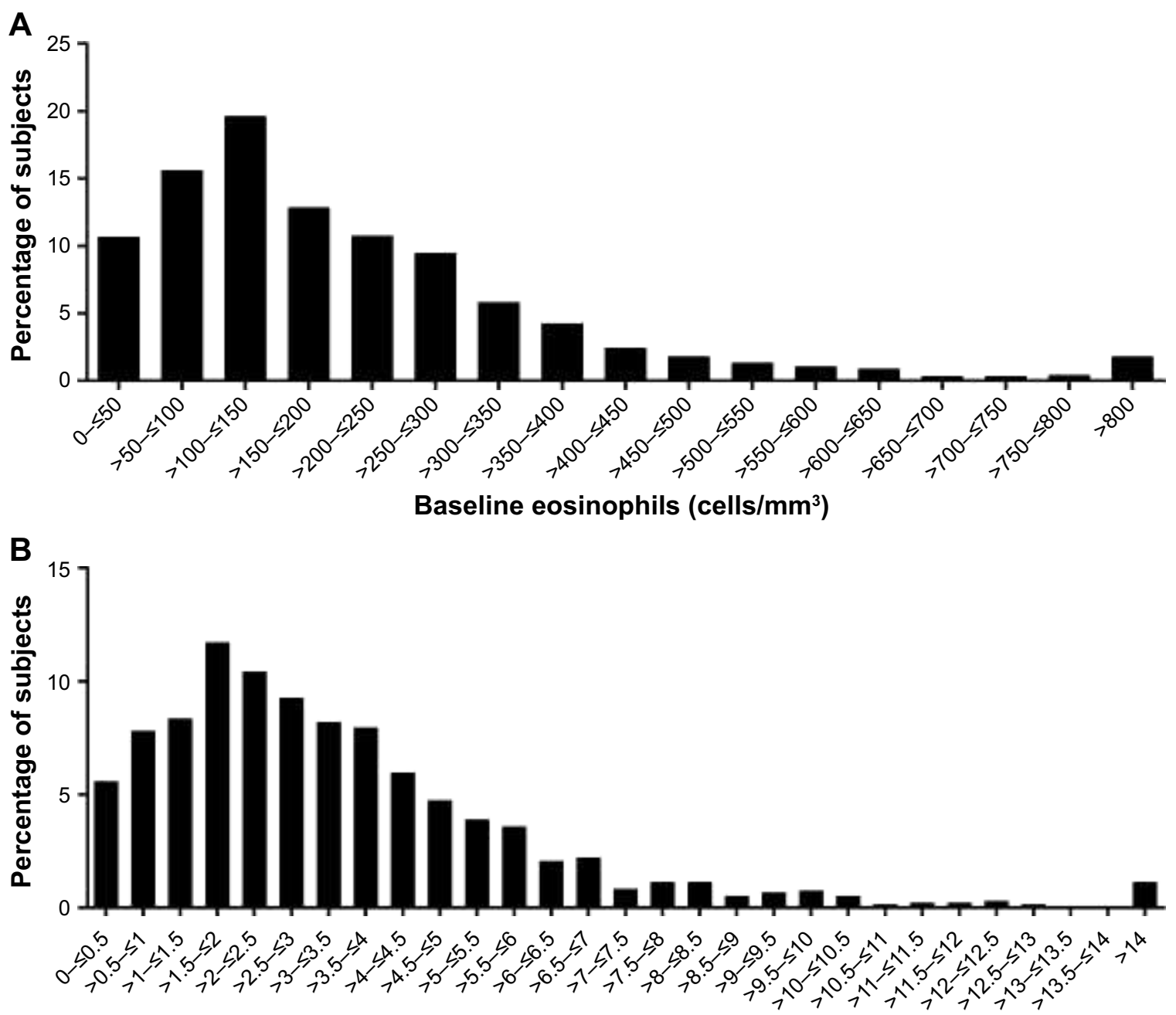

Baseline eosinophils (\%)

Figure 2 Distribution of $(\mathbf{A})$ absolute blood eosinophil count and $(\mathbf{B})$ percentage blood eosinophils among Japanese patients with COPD.

Notes: (A) Subjects with eosinophil values $>800$ cells $/ \mathrm{mm}^{3}$ are grouped together in the $>800$ bar. For studies SCOI00646 (NCT00269I26), SCOI00648 (NCT00269087), and SCOII657I (NCT0I607398), subjects in full analysis set population are included. (B) Subjects with eosinophil values $>$ I4\% are grouped together in the $>$ I4 bar. For studies SCOI00646 (NCT00269126), SCOI00648 (NCT00269087), and SCOII657I (NCT0I607398), subjects in full analysis set population are included. (B) Subjects with eosinophil values $>14 \%$ are grouped together in the >I4 bar. For studies SCOI00646 (NCT00269I26), SCOI00648 (NCT00269087), and SCOII657I (NCT0I607398), subjects in the full analysis set population are included. For study SCOII67I7 (NCT0I762800), subjects in the modified ITT population are included.

Abbreviations: COPD, chronic obstructive pulmonary disease; ITT, intention-to-treat.

have been proposed as a potential biomarker of responsiveness to ICS in patients with COPD. ${ }^{1-3}$ The $\geq 2 \%$ cutoff for raised eosinophil levels in COPD patients falls within what has traditionally been considered the normal range. ${ }^{32}$ While the purpose of the current analysis was not to examine associations between ICS response and blood eosinophil counts in Japanese patients, the similar distributions observed in both Japanese and non-Japanese patients suggest that the same cutoff may be used in Japanese populations. However, this requires more formal testing in a comparative analysis of eosinophil response to ICS in Japanese patient populations.

A strength of the current analysis is that it included data from a relatively large sample of Japanese and non-Japanese patients across several studies. This may provide a more representative assessment of blood eosinophil levels than individual studies, as a variety of different studies with different inclusion criteria were included in the analysis. Furthermore, the data from the multi-country studies allowed for a direct comparison of Japanese and non-Japanese patients in studies that used comparable inclusion/exclusion criteria and with measurements obtained over similar periods of time.

The current analysis was limited in that it was a post hoc analysis of several trials with no formal statistical analysis and not a single directly comparative, randomized, clinical trial. The trials also included patients with a wide range of COPD severity and inflammatory conditions. Previous studies have indicated that combined ICS/LABA therapy may benefit COPD patients with higher eosinophil counts. ${ }^{1,3-7}$ 
However, the current study populations mainly comprised patients with infrequent exacerbations and so may not be directly comparable to the populations examined in previous studies. Eosinophil counts may be influenced by smoking history and body mass index, but data on these variables were not available in all trials included in the analysis. A further study limitation is that the clinical diagnosis of COPD used to identify patients for inclusion into these trials was at the discretion of the investigator at the study site, as such there may be differences in the patient characteristics between Japan and other countries. As with all data obtained from randomized, controlled trials with stringent eligibility criteria, the current data may also not be truly generalizable to the wider population of COPD patients in Japan. Not all of the factors that can affect eosinophil cell distribution were investigated, nor were those that can affect eosinophil level (eg, comorbidity, atopy) in each study considered in a statistical manner. Finally, this analysis provides no measure of the stability of blood eosinophil levels in Japanese patients. Despite these limitations, the outcomes of this analysis suggest that blood eosinophil measurements are potential predictors of ICS responsiveness in COPD in Japanese patients.

\section{Conclusion}

Overall, the distribution of blood eosinophil counts in Japanese patients seems comparable with that of nonJapanese patients; although there was a slightly lower median eosinophil count for Japanese patients in multi-country studies compared with non-Japanese patients in the same studies. The current post hoc analysis provides support for further exploration of the utility of blood eosinophil counts in Japanese patients. Prospective studies examining the predictive validity of blood eosinophil counts as a marker of ICS responsiveness in Japanese COPD patients are warranted.

\section{Previous presentation of data}

These data were presented at a scientific meeting, the Japanese Respiratory Society 2017, held between 21 and 23 April, in a presentation: "Blood eosinophil levels in Japanese COPD patients" by Takeo Ishii, Dawn Midwinter, Mark James, Emma Hilton, Paul Jones, and Neil Barnes.

\section{Acknowledgments}

The authors are grateful to the participants in all studies for their participation and also thank all trial center staff and investigators. The authors would also like to thank the GlaxoSmithKline team members for their input into this manuscript. We also gratefully acknowledge Sandra Williams (Veramed, Stockley Park, UK) for assistance with programming.

All included studies (SCO100646 [NCT00269126], SCO100648 [NCT00269087], HZC114156 [NCT01192191], DB2115362 [NCT01376388], AC4115361 [NCT01702363], SCO116571 [NCT01607398], SCO116717 [NCT01762800], HZC112206 [NCT01053988], HZC112207 [NCT01054885], DB2113361 [NCT01313637], DB2113373 [NCT01313650], and AC4115408 [NCT01387230]), as well as the current post hoc analysis, were funded by GlaxoSmithKline.

The authors would like to acknowledge Angela Rogers, $\mathrm{PhD}$, of Gardiner-Caldwell Communications, Macclesfield, UK, for medical writing support during the development of this manuscript, which was funded by GlaxoSmithKline.

\section{Author contributions}

The authors were fully responsible for the decision to submit the article for publication and for all content and editorial decisions, were involved at all stages of manuscript development, approved the final version for submission, and have met the criteria for authorship as established by the ICMJE.

\section{Disclosure}

All authors, except NH, are full-time employees of Glaxo SmithKline and hold GlaxoSmithKline shares. NH declares research grants to his department from GlaxoSmithKline, as well as consulting fees from GlaxoSmithKline and other pharmaceutical companies. The authors report no other conflicts of interest in this work.

\section{References}

1. Pascoe S, Locantore N, Dransfield MT, Barnes NC, Pavord ID. Blood eosinophil counts, exacerbations, and response to the addition of inhaled fluticasone furoate to vilanterol in patients with chronic obstructive pulmonary disease: a secondary analysis of data from two parallel randomised controlled trials. Lancet Respir Med. 2015;3(6):435-442.

2. Siddiqui SH, Guasconi A, Vestbo J, et al. Blood eosinophils: a biomarker of response to extrafine beclomethasone/formoterol in chronic obstructive pulmonary disease. Am J Respir Crit Care Med. 2015; 192(4):523-525.

3. Pavord ID, Lettis S, Locantore N, et al. Blood eosinophils and inhaled corticosteroid/long-acting beta-2 agonist efficacy in COPD. Thorax. 2016;71(2):118-125

4. Bafadhel M, McKenna S, Terry S, et al. Blood eosinophils to direct corticosteroid treatment of exacerbations of chronic obstructive pulmonary disease: a randomized placebo-controlled trial. Am J Respir Crit Care Med. 2012;186(1):48-55.

5. Bafadhel M, Davies L, Calverley PM, Aaron SD, Brightling CE, Pavord ID. Blood eosinophil guided prednisolone therapy for exacerbations of COPD: a further analysis. Eur Respir J. 2014;44(3):789-791.

6. Barnes N, Sharma R, Lettis S, Calverley PM. Blood eosinophils as a marker of response to inhaled corticosteroids in COPD. Eur Respir J. 2016;47(5):1374-1382. 
7. Watz H, Tetzlaff K, Wouters EF, et al. Blood eosinophil count and exacerbations in severe chronic obstructive pulmonary disease after withdrawal of inhaled corticosteroids: a post-hoc analysis of the WISDOM trial. Lancet Respir Med. 2016;4(5):390-398.

8. Hizawa N. Clinical approaches towards asthma and chronic obstructive pulmonary disease based on the heterogeneity of disease pathogenesis. Clin Exp Allergy. 2016;46(5):678-687.

9. Global Strategy for the Diagnosis, Management and Prevention of COPD [homepage on the Internet]. Global Initiative for Chronic Obstructive Lung Disease (GOLD); 2017. Available from: http:// goldcopd.org. Accessed January 16, 2017.

10. Bain B, Seed M, Godsland I. Normal values for peripheral blood white cell counts in women of four different ethnic origins. J Clin Pathol. 1984;37(2):188-193.

11. Scott KA, Wardlaw AJ. Eosinophilic airway disorders. Semin Respir Crit Care Med. 2006;27(2):128-133.

12. Murphy K. Janeway's Immunobiology. 8th ed. New York: Garland Science; 2012.

13. Szefler SJ, Wenzel S, Brown R, et al. Asthma outcomes: biomarkers. J Allergy Clin Immunol. 2012;129(3 Suppl):S9-S23.

14. Christensen RD, Hill HR. Exercise-induced changes in the blood concentration of leukocyte populations in teenage athletes. Am J Pediatr Hematol Oncol. 1987;9(2):140-142.

15. Kreindler JL, Locantore N, Watkins ML, Lettis S, Tal-Singer R. Minimal effect of inhaled corticosteroids on blood eosinopil count in steroid-naïve COPD patients. Abstract No. 853109. ERS International Conference, Amsterdam, 2015.

16. Kreindler JL, Watkins ML, Lettis S, Tal-Singer R, Locantore N. Effect of inhaled corticosteroids on blood eosinophil count in steroid-naïve patients with COPD. BMJ Open Respir Res. 2016;3(1):e000151.

17. Hilton E, Compton C, Midwinter D, Barnes N. The distribution of blood eosinophil count in a COPD clinical trials database: comparing the UK with the rest of the world. Thorax. 2016;71(Suppl 3):A159-A160.

18. Asai K, Kobayashi A, Makihara Y, Johnson M. Anti-inflammatory effects of salmeterol/fluticasone propionate 50/250 mcg combination therapy in Japanese patients with chronic obstructive pulmonary disease. Int J Chron Obstruct Pulmon Dis. 2015;10:803-811.

19. Betsuyaku T, Kato M, Fujimoto K, et al. A study to assess COPD symptom-based management and to optimise treatment strategy in Japan (COSMOS-J) based on GOLD 2011. Int J Chron Obstruct Pulmon Dis. 2013;8:453-459.
20. Svedsater H, Dale P, Garrill K, Walker R, Woepse MW. Qualitative assessment of attributes and ease of use of the ELLIPTA ${ }^{\mathrm{TM}}$ dry powder inhaler for delivery of maintenance therapy for asthma and COPD. BMC Pulm Med. 2013;13:72.

21. Celli B, Crater G, Kilbride S, et al. Once-daily umeclidinium/ vilanterol 125/25 mcg in COPD: a randomized, controlled study. Chest. 2014;145(5):981-991.

22. Donohue JF, Maleki-Yazdi MR, Kilbride S, Mehta R, Kalberg C, Church A. Efficacy and safety of once-daily umeclidinium/vilanterol 62.5/25 mcg in COPD. Respir Med. 2013;107(10):1538-1546.

23. Trivedi R, Richard N, Mehta R, Church A. Umeclidinium in patients with COPD: a randomised, placebo-controlled study. Eur Respir J. 2014; 43(1):72-81.

24. Takahashi T, Ichinose M, Inoue H, Shirato K, Hattori T, Takishima T. Underdiagnosis and undertreatment of COPD in primary care settings. Respirology. 2003;8(4):504-508.

25. Fukuchi $Y$, Nishimura M, Ichinose M, et al. COPD in Japan: the Nippon COPD epidemiology study. Respirology. 2004;9(4):458-465.

26. Omori H, Nonami Y, Mihara S, Marubayashi T, Morimoto Y, Aizawa H. Prevalence of airflow limitation on medical check-up in Japanese subjects. J UOEH. 2007;29(3):209-219.

27. Onishi K, Yoshimoto D, Hagan GW, Jones PW. Prevalence of airflow limitation in outpatients with cardiovascular diseases in Japan. Int $J$ Chron Obstruct Pulmon Dis. 2014;9:563-568.

28. Yoshimoto D, Nakano Y, Onishi K, Hagan G, Jones P. The relationship between the COPD Assessment Test score and airflow limitation in Japan in patients aged over 40 years with a smoking history. Int $J$ Chron Obstruct Pulmon Dis. 2014;9:1357-1363.

29. Ni W, Shao X, Cai X, et al. Prophylactic use of macrolide antibiotics for the prevention of chronic obstructive pulmonary disease exacerbation: a meta-analysis. PLoS One. 2015;10:e0121257.

30. Amayasu H, Yoshida S, Ebana S, et al. Clarithromycin suppresses bronchial hyperresponsiveness associated with eosinophilic inflammation in patients with asthma. Ann Allergy Asthma Immunol. 2000;84: 594-598.

31. Barnes N, Pavord I, Jones PW, et al. Blood eosinophil count as a predictor of response to inhaled corticosteroids (ICS) in COPD. Am J Respir Crit Care Med. 2015;191:A3975.

32. George L, Brightling C. Eosinophilic airway inflammation: role in asthma and chronic obstructive pulmonary disease. Ther Adv Chronic Dis. 2016;7(1):34-51.
International Journal of COPD

\section{Publish your work in this journal}

The International Journal of COPD is an international, peer-reviewed journal of therapeutics and pharmacology focusing on concise rapid reporting of clinical studies and reviews in COPD. Special focus is given to the pathophysiological processes underlying the disease, intervention programs, patient focused education, and self management protocols.

\section{Dovepress}

This journal is indexed on PubMed Central, MedLine and CAS. The manuscript management system is completely online and includes a very quick and fair peer-review system, which is all easy to use. Visit http://www.dovepress.com/testimonials.php to read real quotes from published authors. 